J. Natn. Sci. Coun. Sri Lanka $199220(2): 237-250$

\title{
BIOLOGICAL TREATMENT OF DISTILLERY WASTE
}

\author{
AMARA S. BELING, W.G. ARIYAWATHIE NISSANKA AND \\ KANTHI ABEYNAYAKE \\ Department of Botany, University of Colombo, P.O. Box 1490, Colombo 3.
}

\author{
(Date of receipt : 11 December 1990) \\ (Date of acceptance : 08 July 1992)
}

\begin{abstract}
The spent wash from distilleries that produce arrack from coconut toddy, is a major source of environmental pollution in the Kalutara district of Sri Lanka. The preliminary studies reported here show that, in Sri Lanka, biological treatment using aerobic and anaerobic systems can be used to successfully treat the spent wash, after dilution, $\mathrm{pH}$ adjustment and introduction of aerobic/anaerobic organisms. Aerobic treatment proved more efficient than the anaerobic treatment for reducing the biochemical oxygen demand of the effluent. Experiments with the effluent from the anaerobic system show that it is possible to use Salvinia molesta, and Eichhornia crassipes for the final polishing. Improving the quality of the effluent however, encouraged the breeding of mosquitoes.
\end{abstract}

\section{INTRODUCTION}

The production of arrack from coconut toddy by the distillery industry is associated with significant environmental pollution in the Kalutara district. ${ }^{1}$ According to the State Distilleries Corporation, the Kalutara district processed about 18,200,000 pure litres (containing $7.5 \%$ alcohol by volume) of toddy in 1990 which is about double that of any other district. Hence the problem of pollution caused by distillery waste is particularly severe in Kalutara. The principal waste, locally referred to as "goda", is the waste water discharged from the alcohol stills after distillation of toddy. Other waste originates from the washing of fermentation vats, floor washings and cooling and condenser waste. ${ }^{2}$ In Sri Lanka, the yeast sludge which deposits in the fermenters is drained along with the spent wash, a process which adds to the pollution. The spent wash from the distilleries is at a high temperature, has a high biochemical oxygen demand (BOD) and a large amount of suspended solids. It is also acidic and highly turbid. The values for suspended solids, BOD and $\mathrm{pH}$ in distillery waste are often above the permissible values specified by the Central Environmental Authority standards for the discharge of industrial effluents into inland surface waters. The polluting effects of the waste water of the distillery on a water course are multiple in nature ${ }^{2}$ The high temperature of the waste can kill fish and other organisms. The acidity in the waste can also destroy the aquatic organisms and inhibit the self purification of streams. Suspended solids can settle at the bottom and destroy fish breeding areas. The greatest damage is caused by the high concentration of readily decomposable organic matter present in the waste water. This causes rapid depletion of the oxygen content of water, creates foul smells, promotes growth of nuisance 
organisms and renders the water course unfit for propagating fish and for drinking. Three methods are available for the treatment of spent wash of an alcohol distillery. ${ }^{2}$ These are, 1) evaporation and incineration of the waste, to generate steam and recover potash - rich ash, 2) anaerobic digestion in closed digesters to recover fuel gas (methane) followed by aerobic biological treatment and 3) anaerobic lagooning followed by aerobic biological treatment in aerated lagoon or oxidation ditch. The use of anaerobic and aerated lagoons costs less than the other methods. ${ }^{2}$ However, this process requires a large land area owing to the slow rate of stabilization of organic matter present in the waste water. In India, to obtain between $80-90 \%$ BOD removal from the spent wash, a residence time of 70-120 days in the lagoons is reported to be required. ${ }^{2}$ Some of the drawbacks observed in the lagooning of waste water of alcohol distilleries in India were, the contamination of ground water due to seepage, foul odours, incomplete treatment and the high cost and restricted availability of land. ${ }^{2}$ Anaerobic digestion of spent wash in a closed digestor is a quicker process for removing $\mathrm{BOD}$ and requires less space and avoids problems of ground water contamination and smells. An additional advantage of this method is that the methane obtained as a by product can be utilized as a fuel. ${ }^{2}$ There is also at present extensive literature available on the use of aquatic plants for waste water treatment. ${ }^{3}$

At present, there is little or no treatment of effluents from distilleries in Sri Lanka. The effluent either contaminates the environment slowly from the storage tanks or is discharged directly into water courses. Preliminary studies on the feasibility of biologically treating distillery waste are reported here.

\section{METHODS AND MATERIALS}

\section{Effluent Source}

For this study, effluent was collected from a particular distillery in the district. This distillery produced effluents between $13500-33700 \mathrm{l} /$ day. Fresh effluent samples were collected into 201 plastic containers as it was being discharged from the main outlet. The samples were stored in the laboratory at $25^{\circ} \mathrm{C}$. Five day biochemical oxygen demand $\left(\mathrm{BOD}_{5}\right), \mathrm{pH}$,turbidity and suspended solid values of the effluent were determined and the amount of effluent produced per day was also noted (Table 1). The $\mathrm{BOD}_{5}$ was determined for 5 days at $20^{\circ} \mathrm{C}$ according to the American Public Health Asssociation, ${ }^{4} \mathrm{pH}$ was measured using a $\mathrm{pH}$ meter, turbidity was measured using a turbidity meter (HACH model 16800) and suspended solids were determined after drying in an oven at $110^{\circ} \mathrm{C}$.

\section{Aerobic and anaerobic treatment of distillery waste}

a) Determination of the optimal dilution for aerobic/anaerobic treatment: A dilution series was made by diluting the effluent $1.7,3.3$, and 10 times with distilled water. The dilutions were calculated assuming the BOD of the effluent to be around 
approximately $10,000 \mathrm{mg} / \mathrm{l}$. The dilution series thus had approximate BOD values of $6000 \mathrm{mg} / \mathrm{l}, 3000 \mathrm{mg} / \mathrm{l}$ and $1000 \mathrm{mg} / \mathrm{l}$. The $\mathrm{pH}$ value was adjusted to 7.0 using $20 \%$ $\mathrm{K}_{2} \mathrm{CO}_{3}$ since this was more effective than $\mathrm{KOH}$ or $\mathrm{NaOH}$. The experiment was carried out in rectangular glass tanks $(24 \times 16 \times 19 \mathrm{~cm})$ which had an outlet at the upper region to limit the capacity to five litres. Two treatments were carried out at room temperature $\left(28^{\circ} \mathrm{C}\right)$ viz. aerobic and anaerobic treatment and a control. In each case 51 of the diluted effluent were used per tank. Five plastic meshes each $10.7 \mathrm{~cm}$ in diameter and $8.0 \mathrm{~mm}$ mesh size were suspended in each tank to provide an additional surface for attachment of the micro-organisms. For the aerobic treatment, the effluent was aerated with an air pump connected to a plastic tube lying along the bottom of the tank and fitted with hypodermic needles between each of the suspended plastic meshes to distribute air through the system. For the anaerobic treatment, the tanks were covered with glass sheets to minimize contact with atmospheric oxygen (Figure 1). Freshly collected activated sludge and anaerobic digester sludge from a sewage treatment plant were introduced into the aerobic and anaerobic systems (10 g/) respectively. The treatment tanks were monitored daily for changes.

b) Aerobic and anaerobic treatment of diluted distillery waste : Based on the results of the above experiment ten times diluted neutralized effluent $\left(\mathrm{BOD}_{5}\right.$ approximately $1000 \mathrm{mg} /$ ) was selected for subsequent experiments. The BOD value for the diluted effluent was determined. The treatment tanks were set up as (a) above. After two weeks, 11 of ten times diluted neutralized distillery effluent was introduced into the bottom of each tank daily for 37 days. When fresh effluent was being added to the aerobic system, the air pump was turned off so that fresh effluent would not overflow from the system without undergoing treatment. The effluent that overflowed from treatment tanks (primary effluent) was collected in sedimentation tanks similar in size to those of the treatment tanks. The effluent that overflowed from the sedimentation tank (secondary effluent) was collected in beakers for the anaerobic system (Figure 2). The BOD value of the effluent at the beginning and in the treatment tanks before first addition of fresh effluent at two weeks was determined and is given in Table 2. The BOD and turbidity of the primary and secondary effluents of the anaerobic set up and the primary effluent of the aerobic set up were measured. The results are presented in Figures 3 and 4 from 19 days after commencement of the experiment or from 5 days after the addition of fresh effluent was initiated.

\section{Use of aquatic plants for the treatment}

Even though the effluent improved more with aerobic digestion, due to the cost that would be involved in aeration of vast quantities of effluent generated in the distillery industry, if aerobic digestion was selected as the method of treatment, only the secondary effluent of the anaerobic set up was selected for use in experiment 2. 


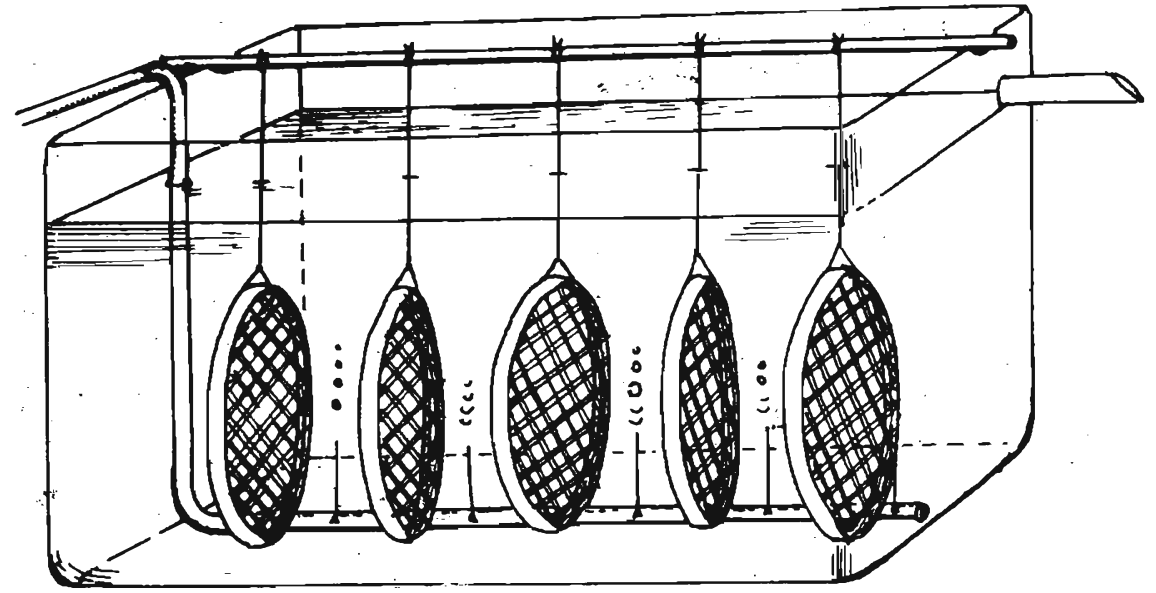

aerobic treatment tank

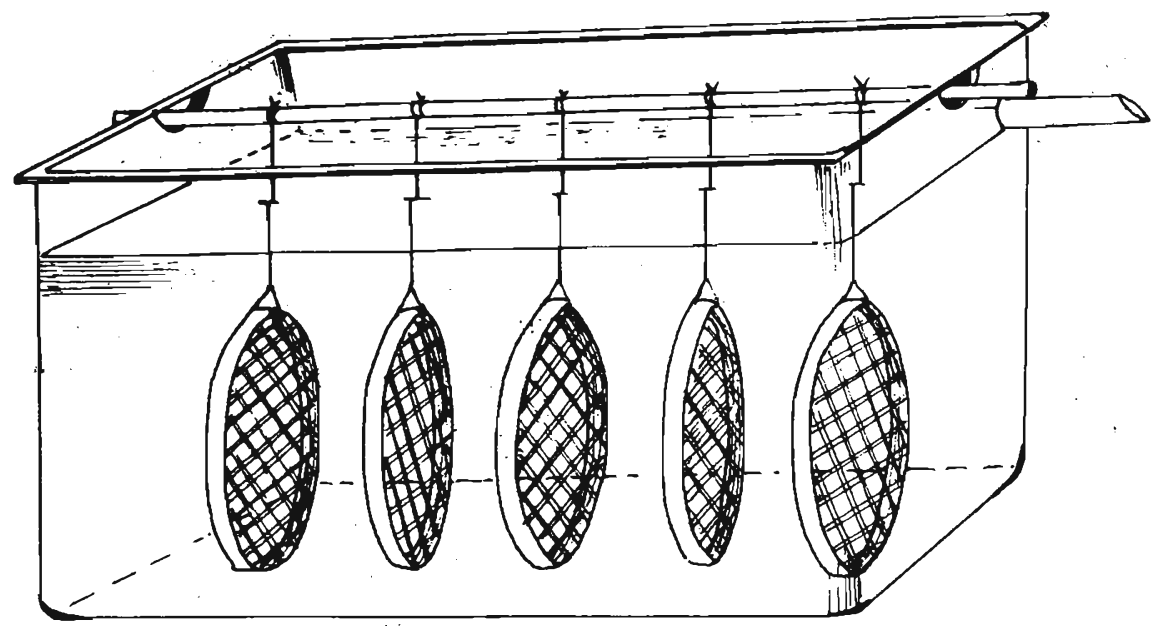

anaerobic treatment tank

Figure 1: Aerobic and anaerobic digestion of distillary waste. 


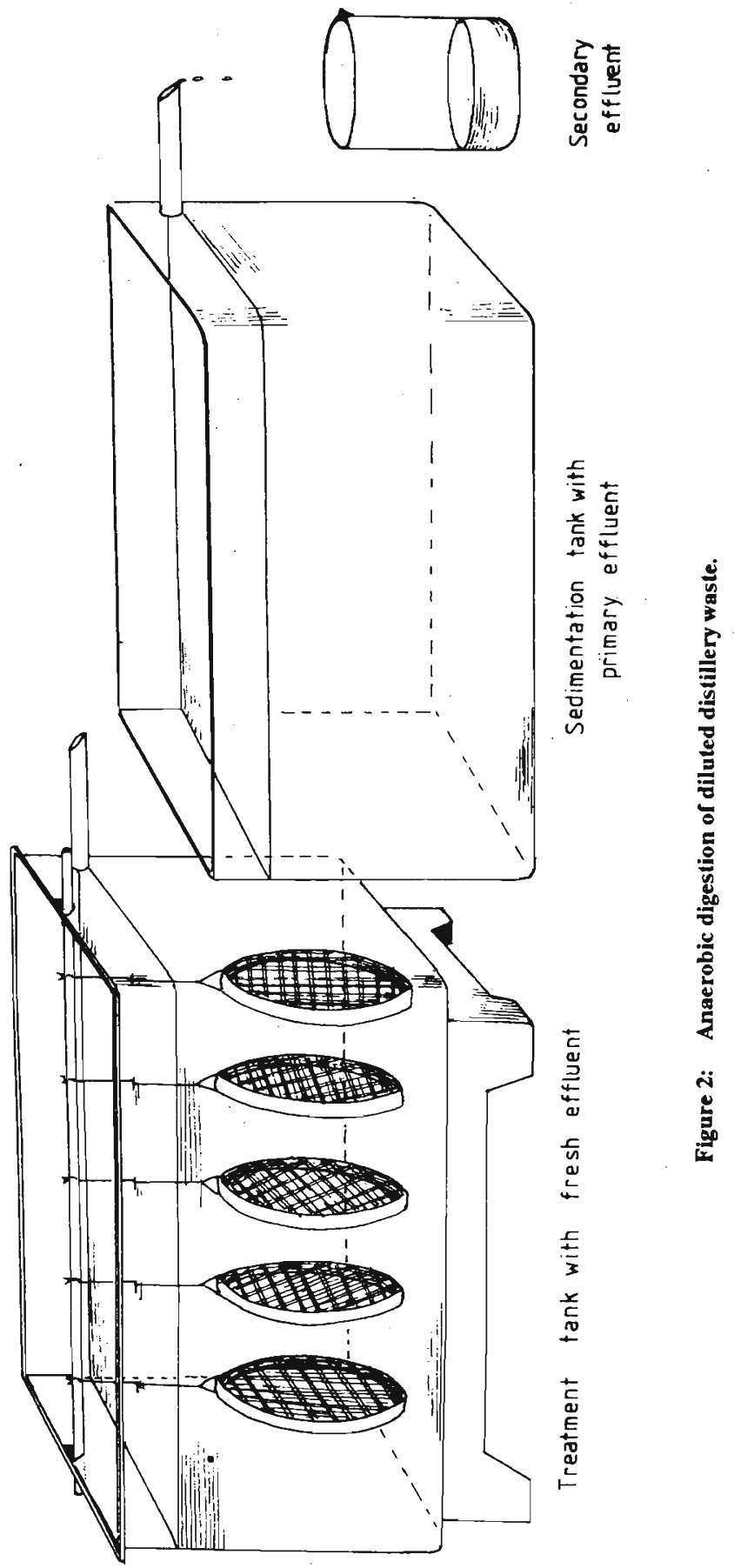


a) Selection of aquatic plants: The secondary effluent of the anaerobic system of experiment $b$ was used in this experiment. The following aquatic plants were selected for this study :- Azolla pinnata, Ceratophyllum demersum, Eichhomia crassipes, Lemna polymhiza, Limnocharis flava, Pistia stratiotes, and Salvinia molesta. The plants were washed well, withered parts removed, and then acclimatized in pretreated distillery effluent. Since the effluent overflow per day was insufficient to start the entire experiment at the same time, different plants were used with the overflow of a particular day. In each case the initial $\mathrm{BOD}_{5}$ value was determined. $500 \mathrm{ml}$ of the secondary effluent was collected in a $1 \mathrm{l}$ beaker and $0.7 \mathrm{~g}$ (fresh weight) of a particular plant was introduced. The amount of plant was selected based on quantity of Azolla, Pistia and Salvinia needed to cover the surface of the effluent in the beaker. This same quantity $(0.7 \mathrm{~g})$ of Eichhomia and Limnocharis and Ceratophyllum was used. The plants were allowed to grow for 8 days and the final $\mathrm{BOD}_{5}$ was determined (Table 3 ).

b) Determination of the maximum BOD tolerated by Salvinia and Eichhomia: This experiment was done tu obtain information on whether aerobic /anaerobic treatment could be stopped earlier before treatment with aquatic plants. The effluent was diluted $67,50,25$, and 17 times with distilled water to obtain approximate BOD values of $150,200,400$ and $600 \mathrm{mg} / \mathrm{l}$. The $\mathrm{BOD}_{5}$ of each dilution was measured. The experiment was carried out in $1 \mathrm{l}$ beakers containing $500 \mathrm{ml}$ of effluent. Salvinia and Eichhornia plants were cleaned as in experiment $2 \mathrm{a}$ and $0.7 \mathrm{~g}$ (fresh weight) of each species was allowed to grow in these dilution series in beakers for one week.

c) Determination of the BOD at which the highest reduction would be achieved with Salvinia and Eichhomia: Three series of dilutions were made by diluting the effluent $100,67,50$, and 40 times with distilled water to obtain approximate BOD values of 100 , 150,200 , and $250 \mathrm{mg} / \mathrm{l}$. The BOD level of each dilution was measured and is presented in Table 4. This experiment was carried out in 11 beakers containing $500 \mathrm{ml}$ effluent. To one series of dilutions $0.7 \mathrm{~g}$ of fresh weight of Salvinia was added while $0.7 \mathrm{~g}$ of Eichhomia was added to the other. A control without plants was also maintained. The BOD values were determined after 4 days. The results are presented in Table 4.

\section{RESULTS}

The distillery effluent had higher values for suspended solids, BOD and $\mathrm{pH}$ than the CEA permissible values (Table 1). 
Table 1: Characteristics of the effluent used in the investigation.

\begin{tabular}{lcc}
\hline & & CEA standards \\
\hline Suspended solids (mg/l) & 820 & 50 \\
Turbidity (NTU) & $390-490$ & not specified \\
$\mathrm{pH}$ value & $3.2-3.5$ & $6.0-8.5$ \\
$\mathrm{BOD}_{5}(\mathrm{mg} / \mathrm{l})$ & $10,400-11,250$ & 30 \\
\hline
\end{tabular}
*The CEA standards for effluents discharged into inland surface waters after treatment are given for
comparison.

\section{Aerobic and anaerobic treatment of distillery waste.}

(a) Determination of the optimal dilution for aerobic/anaerobic treatment.

After two weeks it was observed that ten times diluted effluent having an approximate $\mathrm{BOD}_{5}$ of $1000 \mathrm{mg} / \mathrm{l}$ cleared up more rapidly than the control and the effluents diluted 1.7 and 3.3 times in both aerobic and anaerobic systems. Hence this dilution was selected to carry out further experiments.

(b) Aerobic and anaerobic treatment of diluted distillery waste.

For this experiment even though the effuent was diluted to yield a $\mathrm{BOD}_{5}$ of 1000 $\mathrm{mg} / \mathrm{l}$, on determination it was found to be $844 \mathrm{mg} / \mathrm{l}$.

Table 2: $\mathrm{BOD}_{5}$ of effluent in control, aerobic and anaerobic tanks.

\begin{tabular}{lcc}
\hline & day 1 & 2 weeks \\
\hline control tank & $844^{*}$ & $683^{*}$ \\
aerobic tank & 844 & 56 \\
anaerobic tank & 844 & 263 \\
${ }^{*}{ }^{B O D}{ }_{5}$ in mg/l of effluent before addition of fresh effluent.
\end{tabular}

A very marked reduction of BOD during the two weeks in the aerobic and anaerobic tanks was observed (Table 2). The aerobic system produced a greater improvment in effluent quality than the anaerobic system. Figures 3 and 4 show the 
changes in the $\mathrm{BOD}_{5}$ and turbidity respectively, after the start of the daily addition of fresh influent to the aerobic and anaerobic systems. It can be seen from Figure 3 that in terms of BOD, the improvement initiated in the aerobic and anaerobic systems is maintained even when fresh effluent is added for over a month. Here too it can be seen that the aerobic system reduces the BOD more than the anaerobic system. However in terms of turbidity (Figure 4) the anaerobic system yielded lower values than the aerobic system. On comparing the $\mathrm{BOD}_{5}$ and the turbidity values for the primary effluent and the secondary effluent of the anaerobic system Figures 3 and 4, it can be seen that there is no marked difference between the two sets of values. Thus the sharp difference seen between the BOD and turbidity values for the influent and the primary effluent is not exihibited between the primary and secondary effluents indicating that no additional improvement is made by having the sedimentation tank.

It was observed mosquitoes started breeding in the waste water after the BOD values were reduced in the treatment tanks.

\section{Use of aquatic plants for the treatment.}

(a) Selection of aquatic plants for the final polishing of secondary effluent of the anaerobic treatment.

The $\mathrm{BOD}_{5}$ of the secondary effluent of the anaerobic set up when treated with different aquatic plants is presented in Table 3.

It was observed that Salvinia, Eichhomia, Limnocharis and Ceratophyllum produced the greatest reduction in BOD. However Limnocharis is a plant generally rooted in the mud, while Ceratophyllum is a submerged plant. Therefore, for large scale distillery waste treatment, Limnocharis would have to be provided with a substratum for rooting and Ceratophyllum would be difficult to observe and also harvest due to its submerged habit. Hence only Salvinia and Eichhornia were selected for subsequent experiments.

\section{b) Determination of the BOD tolerance of Salvinia and Eichhomia.}

The dilution series on determination of $\mathrm{BOD}_{5}$ values were $225,325,600$ and $950 \mathrm{mg} /$. On examining the plants after one week it was seen that the effluents with $\mathrm{BOD}_{5}$ values 600 and $950 \mathrm{mg} / \mathrm{l}$ were toxic to the plants. The plants could grow and reproduce in the effluents with $B \mathrm{OD}_{5}$ values 225 and $325 \mathrm{mg} / 1$. From this experiment it could be seen that Salvinia and Eichhornia could tolerate $\mathrm{BOD}_{5}$ values from 325 to a value under $600 \mathrm{mg} /$. 


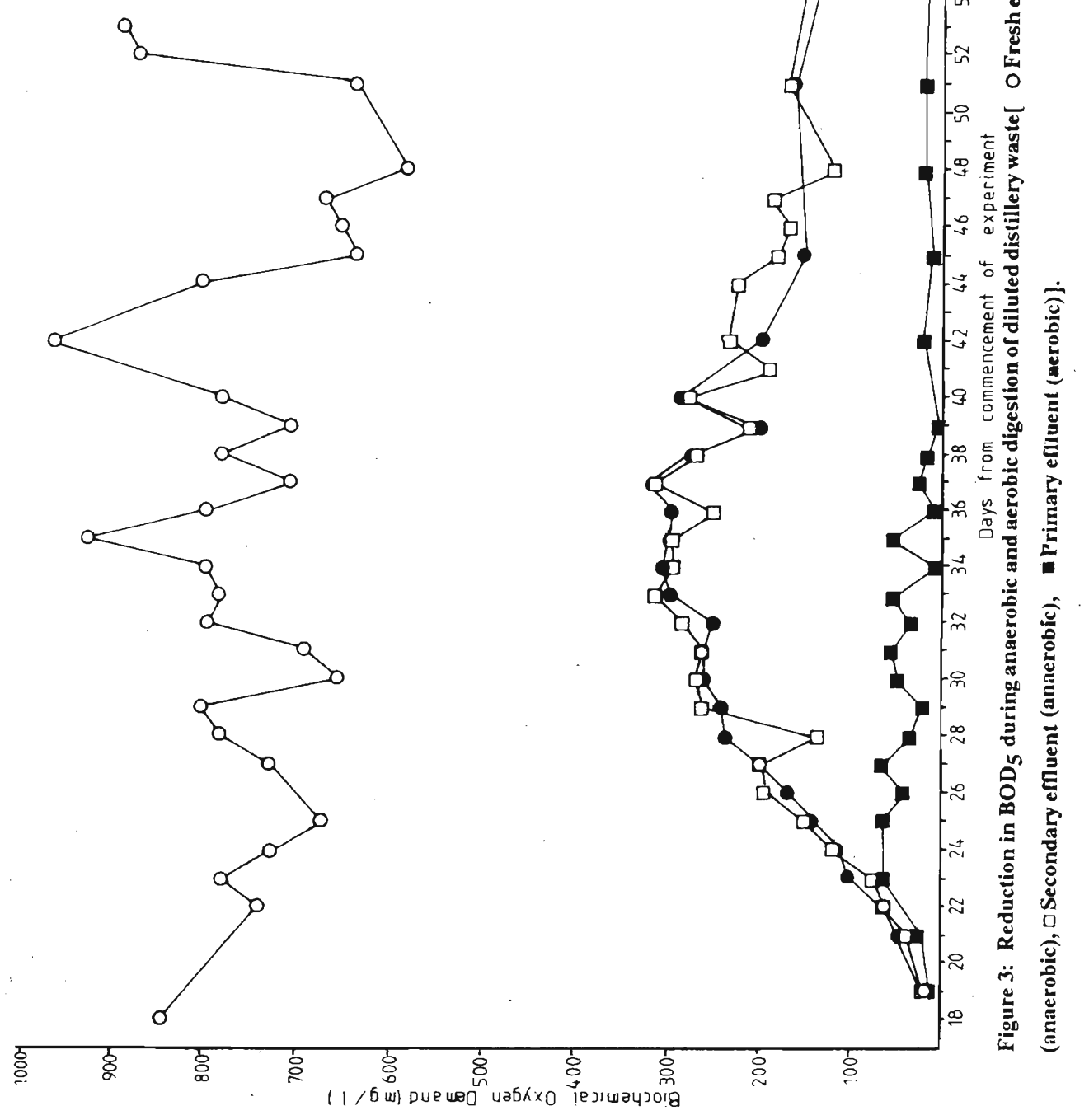




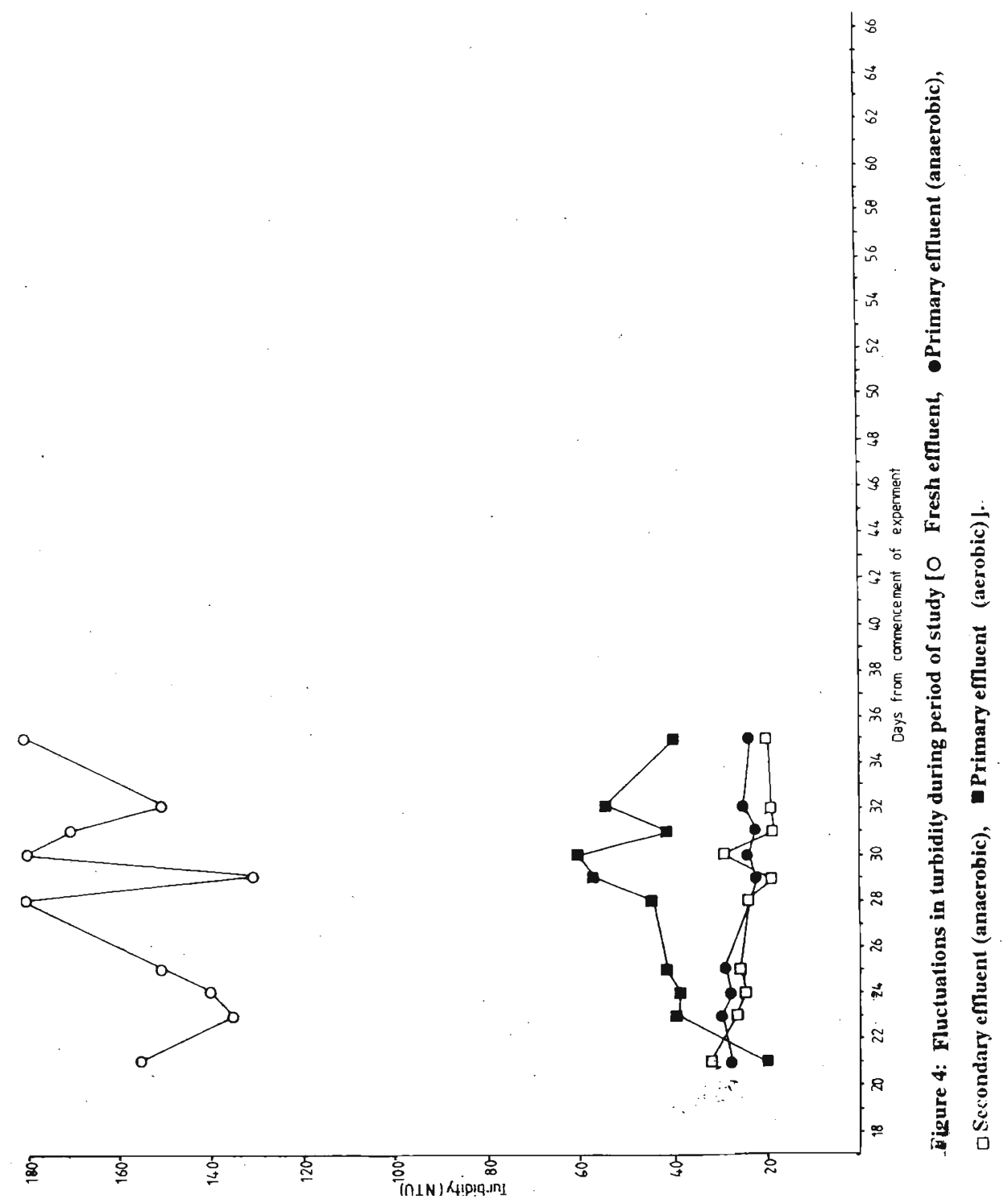


Table 3: Effect of different aquatic plants in reducing the $\mathrm{BOD}_{5}$ of the anaerobic secondary effluent.

\begin{tabular}{lccc}
\hline plant & initial BOD & $\begin{array}{c}\text { mean BOD after } \\
8 \text { Days }\end{array}$ & $\begin{array}{c}\text { \% reduction } \\
\text { in BOD }\end{array}$ \\
\hline $\begin{array}{l}\text { control(without } \\
\text { plants }\end{array}$ & $216 \pm 2^{*}$ & $9 \pm 1$ & 54 \\
Azolla & $279 \pm 1$ & $144 \pm 2$ & 48 \\
Salvinia & $189 \pm 1$ & $41 \pm 2$ & 78 \\
Eichhomia & $234 \pm 3$ & $18 \pm 3$ & 92 \\
Lemna & $225 \pm 5$ & $81 \pm 2$ & 64 \\
Pistia & $180 \pm 2$ & $77 \pm 2$ & 57 \\
Limnocharis & $171 \pm 2$ & $16 \pm 3$ & 90 \\
Ceratophyllum & $189 \pm 3$ & $4 \pm 2$ & 92 \\
\hline
\end{tabular}

mean values and S.E of four replicates in $\mathrm{mg} / \mathrm{l}$.

(c) Determination of the $B O D_{5}$ level at which the highest reduction would be achieved with Salvinia and Eichhomia.

The highest percentage reduction of BOD occurred when the initial $\mathrm{BOD}_{5}$ was $167 \mathrm{mg} / \mathrm{l}$. In terms of the total BOD removed, the maximum removal occurred when the initial BOD $_{5}$ was $230 \mathrm{mg} / \mathrm{l}$.

\section{DISCUSSION}

For distillery waste, the aerobic treatment proved to be faster than the anaerobic treatment. In the aerobic system the $\mathrm{BOD}_{5}$ level was reduced to $56 \mathrm{mg} / \mathrm{l}$ - to a level close to the CEA standards while in the anaerobic treatment the $\mathrm{BOD}_{5}$ level reduced to $263 \mathrm{mg} / \mathrm{l}$ after a retention period of 14 days. The turbidity also decreased considerably both with the aerobic and anaerobic treatment. However, the turbidity values did not reveal that the aerobic treatment was more effective than the anaerobic treatment. Since the suspended solids were not measured during this experiment, a possible explanation to this cannot be offered. However, turbidity could be caused by particles that are not organic in origin, in which case a low BOD will not produce low turbidity. 


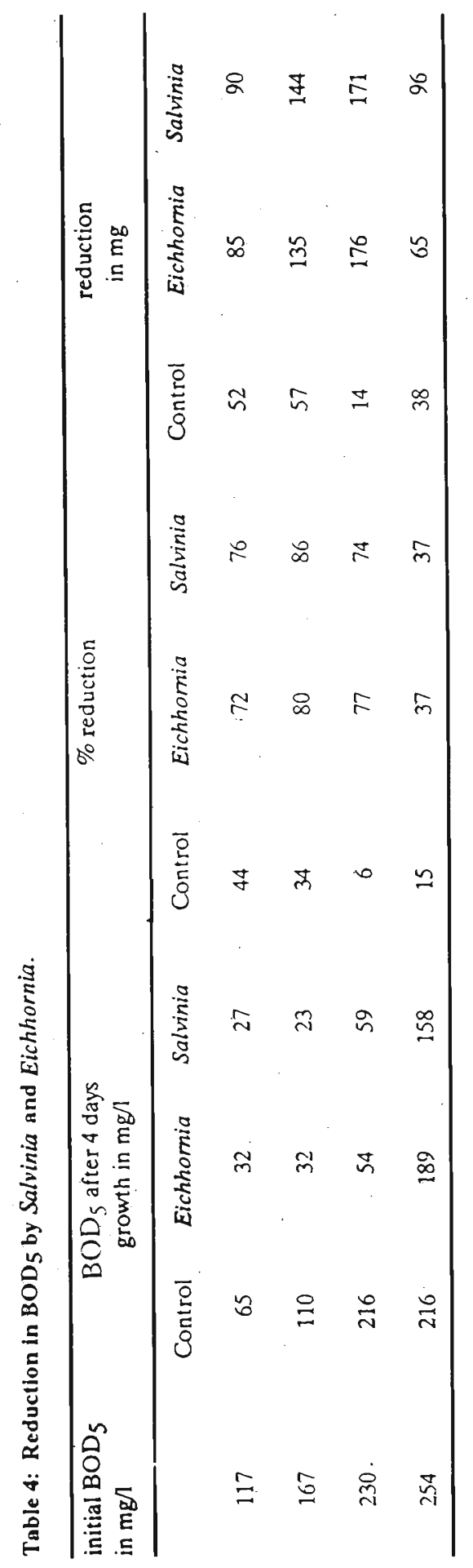


The above results were obtained after dilution, and $\mathrm{pH}$ adjustment of the waste water and on the introduction of aerobic/anaerobic organisms. The best results were obtained when the effluent was diluted ten times to yield a $\mathrm{BOD}_{5}$ of approximately $1000 \mathrm{mg} / \mathrm{l}$ and the $\mathrm{pH}$ was adjusted to 7.0. The necessity for dilution, and thus a large increase in the volume of effluent to be treated, would have to be taken into consideration when a treatment plant is designed. Distillery effluents are usually deficient in nitrogen and phosphorus and these often added to produce an influent ratio of BOD:N:P of 100:5:1 for effective and rapid biological oxidation of organic matter. ${ }^{5}$ No nitrogen or phosphorus was added in the present experiments. 'Better treatment might have been achieved with $\mathrm{N}$ and $\mathrm{P}$ supplements. Even though experiments with the aerobic treatment yielded better results, this system is more expensive and it may be more economical to improve the anaerobic treatment system. The experiments with the aquatic plants showed that it was possible to use Salvinia and Eichhornia for the final polishing of the effluent from the anaerobic system. Since there is no difference between the primary and secondary effluents in terms of BOD and turbidity, the secondary treatment (sedimentation) may be omitted and the plants introduced directly into the sedimentation tanks, and thereby reducing the retention time by 5 days. Thus a BOD 5 of $840 \mathrm{mg} / 1$ could be reduced anaerobically to $260 \mathrm{mg} / \mathrm{l}$ in about 2 weeks, and then further reduced Salvinia and Eichhomia for 8 days. The whole treatment process will thus take about 22 days. Thus for this type of effluent an anaerobic digestion tank follwed by a series of tanks with plants until the required level of BOD achieved is suitable.

In this study the anaerobic treatment was allowed to continue for 2 weeks before any fresh effluent was added. Similarly in the experiment with plants, the plants were allowed to grow for 8 days without adding fresh waste water. In a real waste water treatment system there will be continuous addition of waste water. Therefore, the stability of the system has to be studied when waste water is added daily and the process is operated for a longer period of time.

An important aspect that was made very obvious during these experiments was that when the effluent improved, mosquitoes started breeding in the waste water. This is another problem that would have to be considered in areas where mosquito borne diseases like malaria and filariasis are prevalent. Larvivorous fish can be introdued into the system along with plants for the control of mosquitoes.

The preliminary work carried out shows a possible means for treatment of distillery effluents even though treatment is possible only after increasing the volume of effluent to be treated. By this method it is possible to reduce the BOD of the effluent considerably and bring it down to the values close to CEA standard values before release to the environment. The practical aspects of incorporating this system into the effluent release from distilleries are not considered in this paper. 
The plants that are suitable for the final polishing of distillery effluent Eichhornia and Salvinia are troublesome weeds of aquatic habitats. Hence great care has to be exercised when using these plants for biological treatment. These plants can however be harvested from time to time and used for composting or animal feed.

\section{Acknowledgements}

This work was carried out under the project 'An enviromental profile for the Kalutara district'sponsored by the Central Environmental Authority, Sri Lanka in collaboration with NORAD. We gratefully acknowledge the financial support received from the Central Environmental Authority. We wish to thank Mrs. Suneetha Medis for assisting with the figures, and Mr. Niranjan Udumalagala for typing the manuscript.

\section{References}

1. Abeynayake K. \& Nissanka W.G.A. (1988). An environmental profile for the Kalutara district. A report prepared for the Central Environmental Authority, Sri Lanka.

2. United Nations Economic and Social Commission of Asia and Pacific (1982). Industrial Pollution Control Guidelines. iii. Brewery and Distillery. pp 1-25, ESCAP-Environmental and Development Series, Bangkok.

3. National Academy of Science (1976). Waste water treatment using aquatic weeds. In:Making Aquatic Weeds Useful : Some Perspectives for Developing Countries, Washington D.C.

4. American Public Health Association (1965). Standard methods for the examination of water and wastewater including bottom sediments and sludges, American Public Health Association, Animal Water Works Association and Water Pollution Control Federation.

5. Ripley P. (1979). Process engineering Aspects of the treatment and disposal of distillery effluent. Biochemistry. 14: 8-10. 